\title{
Radiotherapy plays an important role in improving the survival outcome in patients with T1-2N1M0 breast cancer - a joint analysis of 4262 real world cases from two institutions
}

Guang-Yi Sun ${ }^{1 \dagger}$, Ge Wen ${ }^{2,3+}$, Yu-Jing Zhang ${ }^{2 \dagger}$, Yu Tang ${ }^{1}$, Hao Jing ${ }^{1}$, Jian-Yang Wang ${ }^{1}$, Jiang-Hu Zhang ${ }^{1}$, Yong Yang ${ }^{1}$, Xu-Ran Zhao', Si-Ye Chen', Jing Jin', Yong-Wen Song', Yue-Ping Liu', Hui Fang ', Hua Ren', Yuan Tang ${ }^{1}$, Shu-Nan Qi ${ }^{1}$, Ning Li', Bo Chen ${ }^{1}$, Ning-Ning Lu', Shu-Lian Wang ${ }^{1 *}$ (D) and Ye-Xiong Li ${ }^{1 *}$

\begin{abstract}
Background: To compare the survival outcomes between breast-conserving surgery (BCS) and modified radical mastectomy (MRM), and to investigate the role of radiotherapy (RT) in patients with pT1-2N1M0 breast cancer.

Methods: A total of 4262 women with T1-2N1M0 breast cancer treated at two institutions were retrospectively reviewed. A total of 3858 patients underwent MRM, and 832 (21.6\%) of them received postoperative RT (MRM + RT). A total of 404 patients received BCS plus postoperative RT (BCS + RT). All patients received axillary lymph node dissection, while 3.8\% of them had upfront sentinel node biopsy. The association of survival outcomes with different surgical modalities (BCS vs. MRM) and the role of RT were evaluated using multivariable proportional hazards regression and confirmed by the propensity score-matching (PSM) method.
\end{abstract}

\footnotetext{
*Correspondence: wsl20040118@yahoo.com; yexiong12@163.com

Portions of our report were presented in a mini-oral scientific session at the annual meeting of the American Society for Radiation Oncology (ASTRO), September 17, 2019.

${ }^{\dagger}$ Guang-Yi Sun, Ge Wen, and Yu-Jing Zhang contributed equally as co-first authors.

${ }^{1}$ State Key Laboratory of Molecular Oncology and Department of Radiation Oncology, National Cancer Center/National Clinical Research Center for Cancer/Cancer Hospital, Chinese Academy of Medical Sciences and Peking Union Medical College, Beijing 100021, China

Full list of author information is available at the end of the article
}

(C) The Author(s). 2020 Open Access This article is licensed under a Creative Commons Attribution 4.0 International License, which permits use, sharing, adaptation, distribution and reproduction in any medium or format, as long as you give appropriate credit to the original author(s) and the source, provide a link to the Creative Commons licence, and indicate if changes were made. The images or other third party material in this article are included in the article's Creative Commons licence, unless indicated otherwise in a credit line to the material. If material is not included in the article's Creative Commons licence and your intended use is not permitted by statutory regulation or exceeds the permitted use, you will need to obtain permission directly from the copyright holder. To view a copy of this licence, visit http://creativecommons.org/licenses/by/4.0/. The Creative Commons Public Domain Dedication waiver (http://creativecommons.org/publicdomain/zero/1.0/) applies to the data made available in this article, unless otherwise stated in a credit line to the data. 
(Continued from previous page)

Results: At a median follow-up of 71 months (range of 6-230 months), the 5-year overall survival (OS) rates of the BCS and MRM groups were 96.5 and $92.7 \%$, respectively $(P=.001)$, and the corresponding 5-year disease-free-survival (DFS) and locoregional recurrence (LRR) rates were 92.9 and $84.0 \%$, and 2.0 and $7.0 \%(P=.001)$, respectively $(P<.001)$. Multivariate analysis revealed that RT was an independent prognostic factor for improved OS $(P=.001)$ and DFS $(P=.009)$, and decreased LRR $(P<.001)$. However, surgery procedure was not independently associated with either OS $(P=.495)$, DFS $(P=.204)$, or LRR $(P=.996)$, which was confirmed by PSM analysis.

Conclusion: Postoperative radiotherapy rather than the surgery procedures was associated with superior survival outcomes in patients with T1-2N1M0 breast cancer.

Keywords: Breast neoplasm, Breast conserving surgery, Mastectomy, One to three positive nodes, Radiotherapy

\section{Background}

Early randomized trials have demonstrated that breastconserving surgery (BCS) combined with postoperative radiotherapy (RT) can achieve equivalent overall survival compared with MRM for early-stage breast cancer patients [1-5]. Thus, the concept of "less is more" has been widely accepted by surgeons. Currently, some retrospective studies based on the real world population have found that breast-conserving therapy can result in more survival benefits to early-stage breast cancer patients than MRM (Table 1), [6-10] but the reason is unclear. The use of BCS has been relatively low in China [12], and the role of postmastectomy radiotherapy (PMRT) is controversial in T1-2N1M0 breast cancer $[13,14]$. Therefore, we conducted a retrospective analysis to compare the survival outcomes between BCS + RT and MRM patients, and investigated the role of $\mathrm{RT}$ in patients with T1-2N1M0 breast cancer in a real world setting. Our hypothesis was that patients treated with $\mathrm{BCS}+\mathrm{RT}$ had superior survival outcomes and that radiotherapy, rather than surgery procedures, contributed to the improved survival.

\section{Methods}

The study protocol was approved by the Institutional Review Board of Cancer Hospital, Chinese Academy of Medical Sciences and Peking Union Medical College (approval number 15-057/984). No informed consent was sought. A total of 4262 women with pT1-2N1M0 breast cancer treated at two institutions in China between January 1999 and December 2014 were retrospectively reviewed. All patients received lumpectomy or mastectomy and axillary lymph node dissection without neoadjuvant chemotherapy. Primary tumors were $5 \mathrm{~cm}$ or less with one to three positive axillary lymph nodes. All patients that underwent BCS received radiotherapy. PMRT was given to patients who had more high-risk factors, such as younger age, T2, 2-3 positive nodes, less than 10 nodes dissected, lymphovascular invasion (LVI), grade 3, and estrogen receptor

Table 1 Retrospective studies based on the real world population

\begin{tabular}{|c|c|c|c|c|c|}
\hline Studies & $\begin{array}{l}\text { Study } \\
\text { period }\end{array}$ & $\begin{array}{l}\text { Total number of } \\
\text { patients }\end{array}$ & Stage & Group & $\begin{array}{l}\text { Breast cancer death HR } \\
(95 \% \mathrm{Cl})\end{array}$ \\
\hline \multirow[t]{2}{*}{ Hwang, 2013 [6] } & \multirow[t]{2}{*}{ 1990-2004 } & \multirow[t]{2}{*}{112,154} & \multirow[t]{2}{*}{$|-| \mid$} & $M R M \pm R T$ & 1.00 \\
\hline & & & & $\mathrm{BCS}+\mathrm{RT}$ & $0.84(0.78-0.91)$ \\
\hline \multirow[t]{3}{*}{ Agarwal, 2014 [7] } & \multirow[t]{3}{*}{ 1998-2008 } & \multirow[t]{3}{*}{132,149} & \multirow{3}{*}{$\begin{array}{l}|-| \mid \text { (tumor size } \leq 4 \\
\mathrm{~cm})\end{array}$} & $\mathrm{BCS}+\mathrm{RT}$ & 1.00 \\
\hline & & & & $\begin{array}{l}\text { MRM without } \\
\text { RT }\end{array}$ & $1.31(1.25-1.39)$ \\
\hline & & & & $M R M+R T$ & $1.47(1.34-1.61)$ \\
\hline \multirow{2}{*}{$\begin{array}{l}\text { Hartmann-Johnsen, } 2015 \\
\text { [8] }\end{array}$} & \multirow[t]{2}{*}{ 1998-2008 } & \multirow[t]{2}{*}{13,015} & \multirow[t]{2}{*}{ I-II (T1-2N0-1M0) } & $\mathrm{BCS}+\mathrm{RT}$ & 1.00 \\
\hline & & & & $M R M \pm R T$ & $1.64(1.43-1.88)$ \\
\hline \multirow[t]{2}{*}{ Hofvind, 2015 [9] } & \multirow[t]{2}{*}{ 2005-2011 } & \multirow[t]{2}{*}{9.547} & \multirow[t]{2}{*}{$|-|||$} & $\mathrm{BCS}+\mathrm{RT}$ & 1.00 \\
\hline & & & & $M R M \pm R T$ & $1.7(1.3-2.4)$ \\
\hline \multirow[t]{2}{*}{ van Maaren, 2016 [10] } & \multirow[t]{2}{*}{ 2000-2004 } & \multirow[t]{2}{*}{37,207} & \multirow[t]{2}{*}{ I-II (T1-2N0-1M0) } & $M R M \pm R T$ & 1.00 \\
\hline & & & & $\mathrm{BCS}+\mathrm{RT}$ & $0.81(0.78-0.85)$ \\
\hline \multirow[t]{2}{*}{ Christiansen, 2018 [11] } & \multirow[t]{2}{*}{ 1995-2012 } & \multirow[t]{2}{*}{58,331} & \multirow[t]{2}{*}{$|-|||$} & $B C S \pm R T$ & 1.00 \\
\hline & & & & $M R M \pm R T$ & $1.20(1.15-1.25)$ \\
\hline
\end{tabular}


(ER) negative. Clinicopathological data were recorded, including age, date of surgery, tumor morphology, LVI, histological grade, tumor size, nodal status, ER status, progesterone receptor (PR) status, human epidermal growth factor receptor 2 (HER2) status, and information from adjuvant treatments.

Locoregional recurrence (LRR) was defined as a recurrence in the breast/chest wall or in ipsilateral axillary, internal mammary, or supra-/infraclavicular nodes. Overall survival (OS) was defined as the time from the date of the definitive surgery until death from any cause. Disease-free survival (DFS) was defined as the time from the date of the definitive surgery to death or first breast cancer recurrence. The general characteristics of the subjects were expressed as frequencies and percentages and compared using the Fisher exact or $\chi^{2}$ test. Survival rates were calculated by using the Kaplan-Meier method and compared by log-rank test. The association of survival outcomes with potential prognostic factors was tested by univariate Cox regression analysis and further evaluated using multivariable proportional hazards regression. To minimize differences in distribution of covariates between groups, a propensity score matching (PSM) was used which was computed taking into consideration all the possible relevant factors (Table 2) in the analysis. The matching approach was 1:1 nearest neighbor with a caliber of $10 \%$. Statistical analyses were performed using the SPSS Package for Windows, version 23.0 (SPSS Inc., Chicago, IL, USA). A $P$-value of $\leq .05$ was considered statistically significant.

\section{Results}

\section{Patient characteristics}

Table 2 shows the demographic, tumor, and treatment characteristics of the entire patient cohort. The median age was 48 years old (range of 23-84 years old). All patients received axillary lymph node dissection, while $3.8 \%$ of them had upfront sentinel node biopsy. The median number of positive nodes was one (range of 1-3); the median number of dissected nodes was 17 (range of 1-59). A total of 3858 (90.5\%) patients underwent MRM and 404 (9.5\%) patients underwent BCS. The BCS group had more patients treated between 2009 and 2014 compared with the MRM group. A higher number of patients in the BCS group were $\leq 50$ years old, showed potentially favorable characteristics, such as T1 disease, had one positive node, an absence of LVI, grade 1-2 tumors, and positive hormonal receptors compared with MRM group. There were more patients who received chemotherapy, hormone therapy, and anti-HER2 targeted therapy in the BCS group than the MRM group.
Among the 3858 patients who underwent MRM, 832 (21.6\%) received postoperative RT $(\mathrm{MRM}+\mathrm{RT})$. The chest wall was irradiated in 832/832 (100\%) patients, supra-/infraclavicular nodal region was irradiated in $821 / 832$ (98.7\%) patients, axilla was irradiated in $49 / 832$ (5.9\%) patients, and internal mammary chain was irradiated in 79/832 (9.5\%) patients. The median total dose was $50 \mathrm{~Gy}$ (range of $46.8-70 \mathrm{~Gy}$ ) using conventional fractionation in $789 / 832(94.8 \%)$ patients and $43.5 \mathrm{~Gy}$ (range of 40-43.5 Gy) in 15 fractions in 43/832 (5.2\%) patients. A total of 516/832 (62.0\%) patients had information on RT techniques, of which 501 (97.1\%) received two-dimensional radiotherapy, $5(1.0 \%)$ received threedimensional conformal radiotherapy, and 10 (1.9\%) received intensity-modulated radiotherapy.

All 404 patients who underwent BCS received postoperative RT. The whole breast was irradiated in 404/404 (100\%) patients, tumor bed boost was delivered in 365/ $404(90.3 \%)$ patients, supra-/infraclavicular nodal region was irradiated in 107/404 (26.5\%) patients, axilla was irradiated in 3/404 (0.7\%) patients, and internal mammary chain was irradiated in 3/404 (0.7\%). The median dose to the whole breast \pm nodal regions was 50 Gy (range of $48-50$ Gy) using conventional fractionation in 360/404 (90.1\%) patients and $43.5 \mathrm{~Gy}$ in 15 fractions in $44 / 404$ (10.9\%) patients. The median dose to the tumor bed was 10 Gy (range, 10-20 Gy) using conventional fractionation in $321 / 365(87.9 \%)$ patients and $8.7 \mathrm{~Gy}$ in three fractions in $44 / 365$ (12.1\%) patients. A total of 236/404 (58.4\%) patients had information on RT techniques, of which $170(72.0 \%)$ received three-dimensional conformal radiotherapy or intensity-modulated radiotherapy, and 66 (28.0\%) received two-dimensional radiotherapy.

Among the entire cohort, 3995 (93.8\%) patients received adjuvant chemotherapy, with a median of six cycles (range of 1-20). A total of 2482 (62.1\%) patients received anthracycline and taxane-based regimens, $865(21.7 \%)$ patients received anthracyclinebased regimens, 135 (3.4\%) patients received taxanebased regimens, $240(6.0 \%)$ patients received other regimens, and $208(5.2 \%)$ patients received an unknown regimen. A total of 3296/4262 (77.3\%) patients had ER and / or PR positive disease, of which 2862/ 3296 (86.8\%) received hormonal therapy. The median duration of hormonal therapy was 45 months (range of $1-180)$. A total of $859 / 4262(20.2 \%)$ patients had HER2 positive disease, only 233/859 (27.1\%) received anti-HER2 targeted therapy.

\section{Outcome and prognosis}

At the median 71-month (range of 6-230 months) follow-up, $332(7.8 \%)$ patients had locoregional recurrences, whereas 601 (14.1\%) had distant metastases, and $442(10.4 \%)$ patients had died. Among the 442 patients 
Table 2 Baseline characteristics of the entire patient cohort

\begin{tabular}{|c|c|c|c|c|}
\hline & \multicolumn{3}{|l|}{ No. (\%) } & \multirow[t]{2}{*}{$P$} \\
\hline & the entire cohort $(n=4262)$ & $\mathrm{MRM} \pm \mathrm{RT}(n=3858)$ & $\mathrm{BCS}+\mathrm{RT}(n=404)$ & \\
\hline Year & & & & $<.001$ \\
\hline 1999-2008 & $1976(46.4)$ & $1871(48.5)$ & $105(26.0)$ & \\
\hline 2009-2014 & $2286(53.6)$ & $1987(51.5)$ & $299(74.0)$ & \\
\hline Age (years) & & & & $<.001$ \\
\hline$\leq 40$ & $802(18.8)$ & $678(17.6)$ & $124(30.7)$ & \\
\hline$>40$ & $3460(81.2)$ & $3180(82.4)$ & $280(69.3)$ & \\
\hline Tumor location & & & & .755 \\
\hline Inner quadrant & $909(21.3)$ & $819(21.2)$ & $90(22.3)$ & \\
\hline Other quadrants & $3292(77.2)$ & $2985(77.4)$ & $307(76.0)$ & \\
\hline Unknown & $61(1.4)$ & $54(1.4)$ & $7(1.7)$ & \\
\hline T stage & & & & $<.001$ \\
\hline $\mathrm{T} 1$ & $2009(47.1)$ & $1725(44.7)$ & $284(70.3)$ & \\
\hline $\mathrm{T} 2$ & $2253(52.9)$ & $2133(55.3)$ & $120(29.7)$ & \\
\hline SLNB & & & & $<.001$ \\
\hline No & $4099(96.2)$ & $3782(98.0)$ & $317(78.5)$ & \\
\hline Yes & $163(3.8)$ & $76(2.0)$ & $87(21.5)$ & \\
\hline No. of ALND & & & & .834 \\
\hline$\leq 19$ & $2721(63.8)$ & $2465(63.9)$ & $256(63.4)$ & \\
\hline$>19$ & $1541(36.2)$ & $1393(36.1)$ & $148(36.6)$ & \\
\hline No. of positive nodes & & & & .016 \\
\hline 1 & $2198(51.6)$ & $1963(50.9)$ & $235(58.2)$ & \\
\hline 2 & $1264(29.7)$ & $1156(30.0)$ & $108(26.7)$ & \\
\hline 3 & $800(18.8)$ & 739 (19.2) & $61(15.1)$ & \\
\hline Lymphovascular invasion & & & & $<.001$ \\
\hline No & 3457 (81.1) & 3109 (80.6) & $348(86.1)$ & \\
\hline Yes & $522(12.2)$ & $470(12.2)$ & $52(12.9)$ & \\
\hline unknown & $283(6.6)$ & $279(7.2)$ & $4(1.0)$ & \\
\hline Histological grade & & & & $<.001$ \\
\hline । & $133(3.1)$ & $104(2.7)$ & $29(7.2)$ & \\
\hline$\|$ & $2290(53.7)$ & $2035(52.7)$ & $255(63.1)$ & \\
\hline III & $1030(24.2)$ & $937(24.3)$ & $93(23.0)$ & \\
\hline unknown & $809(19.0)$ & $782(20.3)$ & $27(6.7)$ & \\
\hline Chemotherapy & & & & $<.001$ \\
\hline No & $239(5.6)$ & $236(6.1)$ & $3(0.7)$ & \\
\hline Yes & 3995 (93.7) & $3594(93.2)$ & 401 (99.3) & \\
\hline unknown & $28(0.7)$ & $28(0.7)$ & $0(0)$ & \\
\hline Chemotherapeutic drug & & & & $<.001$ \\
\hline Taxane-based & $2684(63.0)$ & $2344(60.8)$ & $340(84.2)$ & \\
\hline Others & $1105(25.9)$ & $1057(27.4)$ & $48(11.9)$ & \\
\hline Unknown & $473(11.1)$ & $457(11.8)$ & $16(4.0)$ & \\
\hline Hormone receptor \& Hormonal therapy & & & & $<.001$ \\
\hline negative \& no & $913(21.4)$ & $862(22.3)$ & $51(12.6)$ & \\
\hline positive \& yes & $2862(67.2)$ & $2537(65.8)$ & $325(80.4)$ & \\
\hline
\end{tabular}


Table 2 Baseline characteristics of the entire patient cohort (Continued)

\begin{tabular}{llll}
\hline & No. $(\%)$ & & \multicolumn{1}{c}{$\boldsymbol{P}$} \\
\cline { 2 - 4 } & the entire cohort $(\boldsymbol{n}=\mathbf{4 2 6 2})$ & MRM \pm RT $(\boldsymbol{n}=\mathbf{3 8 5 8})$ & $\mathbf{B C S}+\mathbf{R T}(\boldsymbol{n}=\mathbf{4 0 4})$ \\
\hline positive \& no & $312(7.3)$ & $295(7.6)$ & $11(2.7)$ \\
Unknown & $175(4.1)$ & $164(4.3)$ & $301(74.5)$ \\
HER2 \& Target therapy & & $2545(66.0)$ & $35(8.7)$ \\
negative \& no & $2846(66.8)$ & $198(5.1)$ & $37(9.2)$ \\
positive \& yes & $233(5.5)$ & $582(15.1)$ & $31(7.7)$ \\
positive \& no & $619(14.5)$ & $533(13.8)$ & 001 \\
unknown & $564(13.2)$ & & \\
\hline
\end{tabular}

Abbreviations: MRM Modified radical mastectomy, BCS Breast-conserving surgery, RT Radiotherapy, SLNB Sentinel lymph node biopsy, ALND Axillary lymph node dissection, HER2 Human epidermal growth factor receptor 2

who died, 483 (86.7\%) died from breast cancer, 4 (0.9\%) died from treatment complications, 47 (10.6\%) died from other causes, and 8 (1.8\%) died from unknown reasons. There was no significant difference in the proportion of patients who died from breast cancer between the MRM and the BCS + RT group (86.9\% vs.95.5\%, $P=.483)$. The 5-year LRR, OS, DFS rates were 2.0 and 7.0\% $(P=.001)$,
96.5 and $92.7 \%(P=.001)$, and 92.9 and $84.0 \%(P<.001)$ for the BCS + RT group and the MRM group, respectively (Fig. 1).

The univariate and multivariate analyses of prognostic factors for LRR, OS and DFS are shown in Table 3. RT was an independent prognostic factor for decreased LRR $(P<.001)$ and improved OS $(P=.001)$ and DFS $(P=$
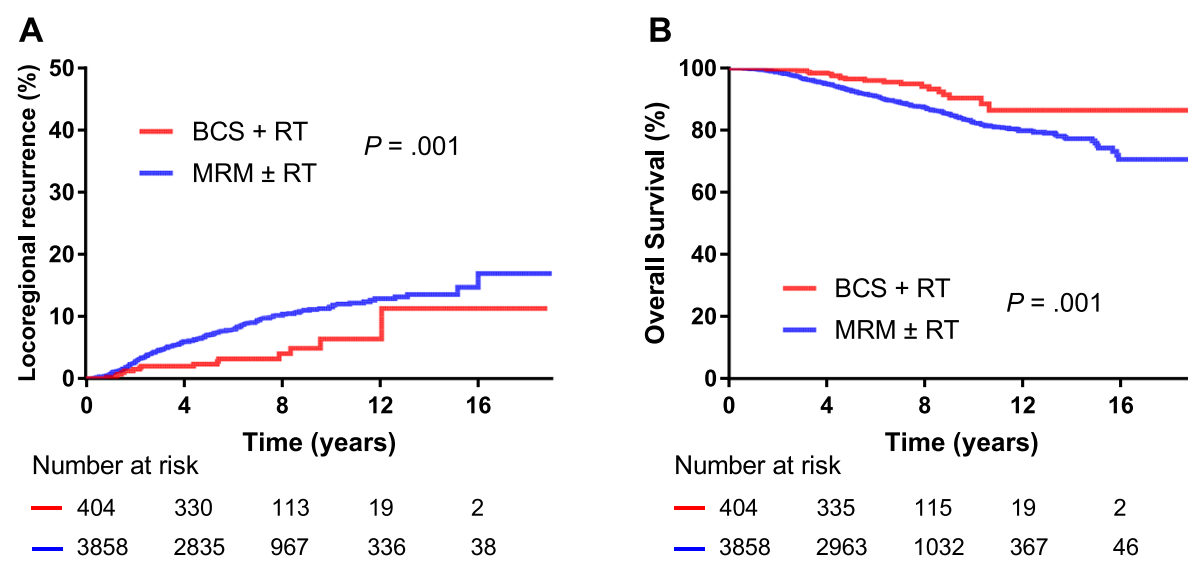

$\begin{array}{lllll}-3858 & 2963 & 1032 & 367 & 46\end{array}$

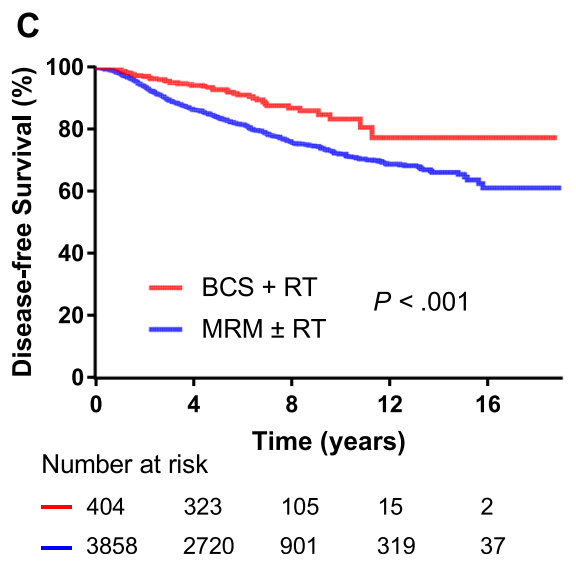

Fig. 1 Kaplan-Meier plots showing locoregional recurrence, overall survival and disease-free survival between the BCS + RT and MRM patient groups. MRM = modified radical mastectomy; BCS = breast-conserving surgery; RT = radiotherapy. 


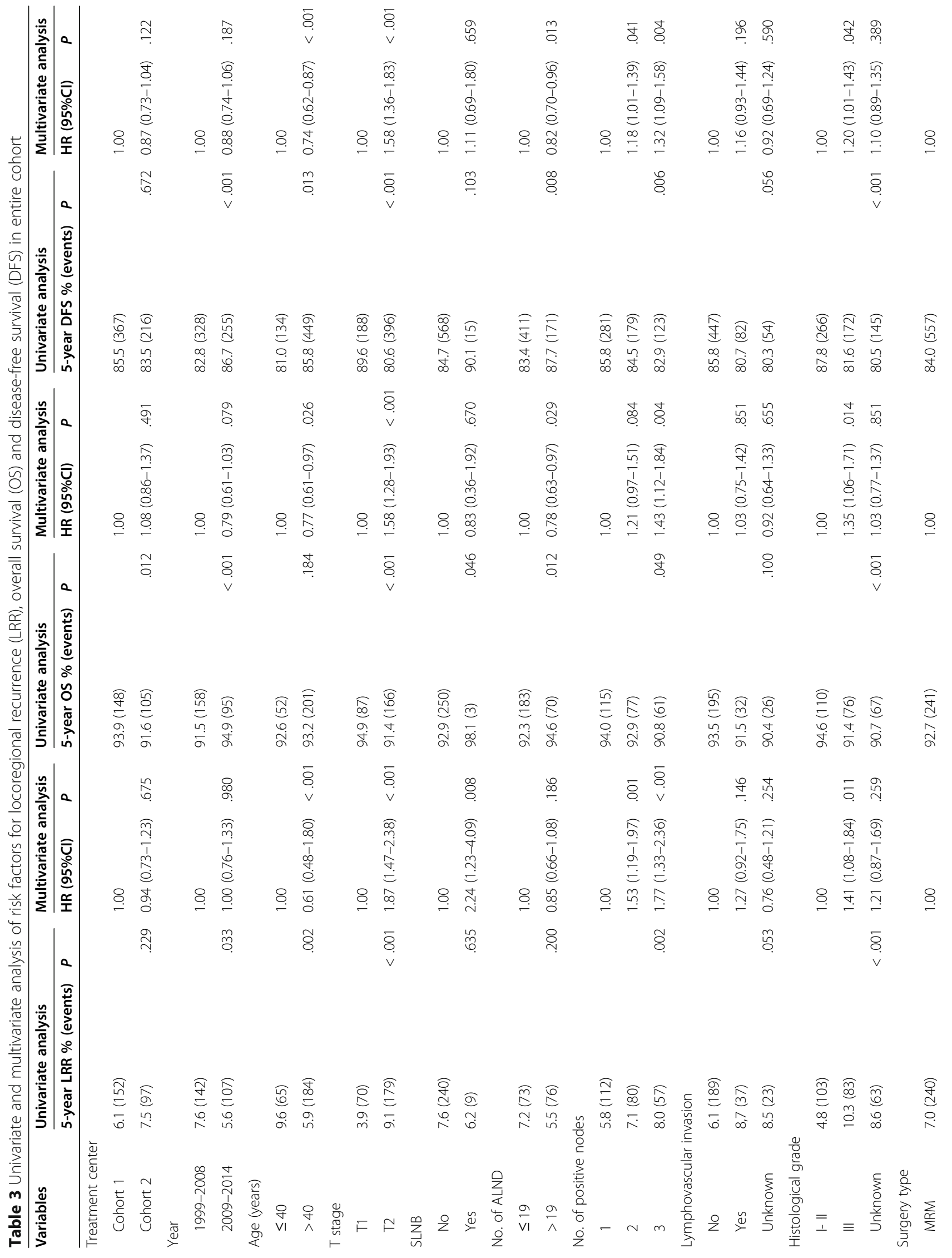




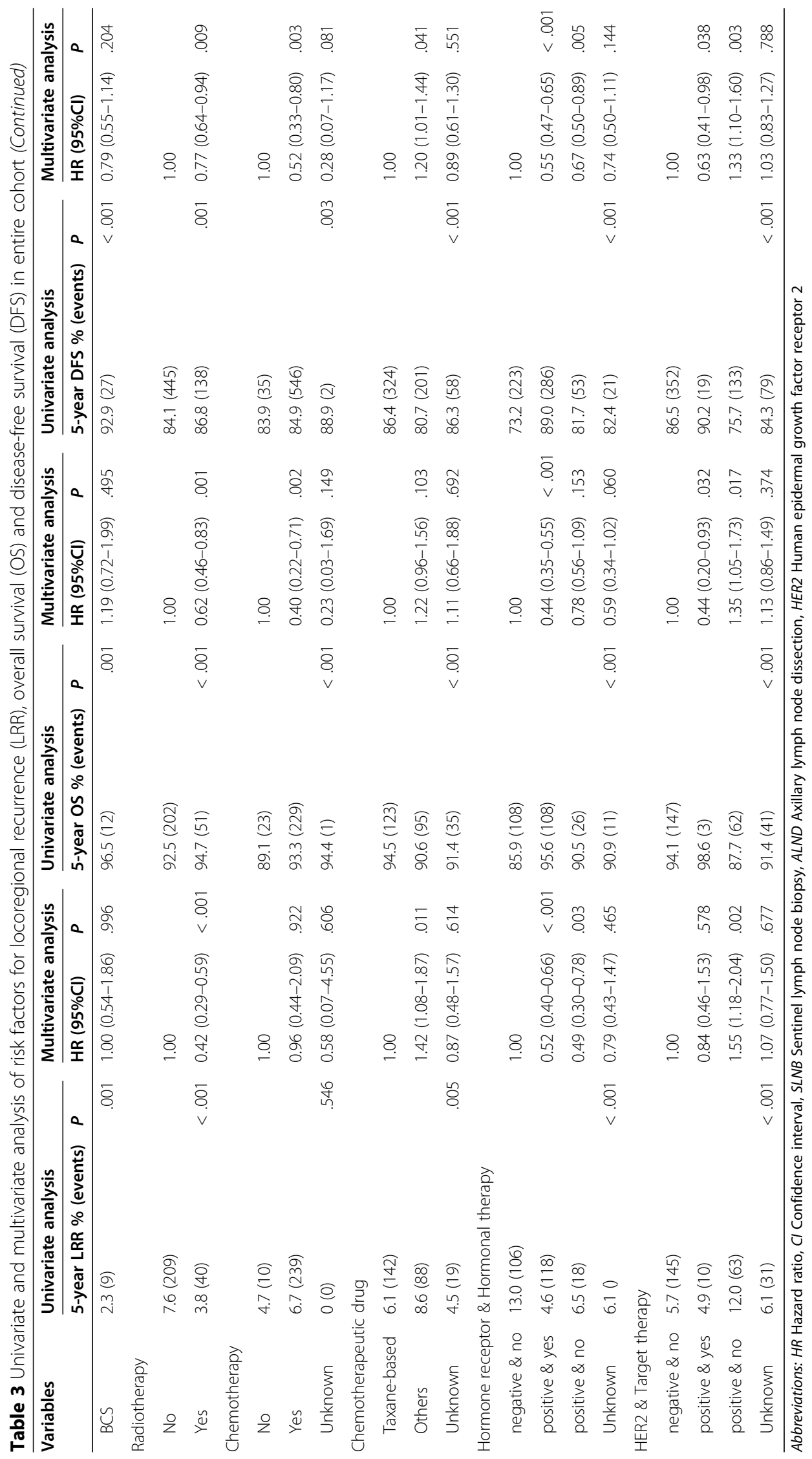



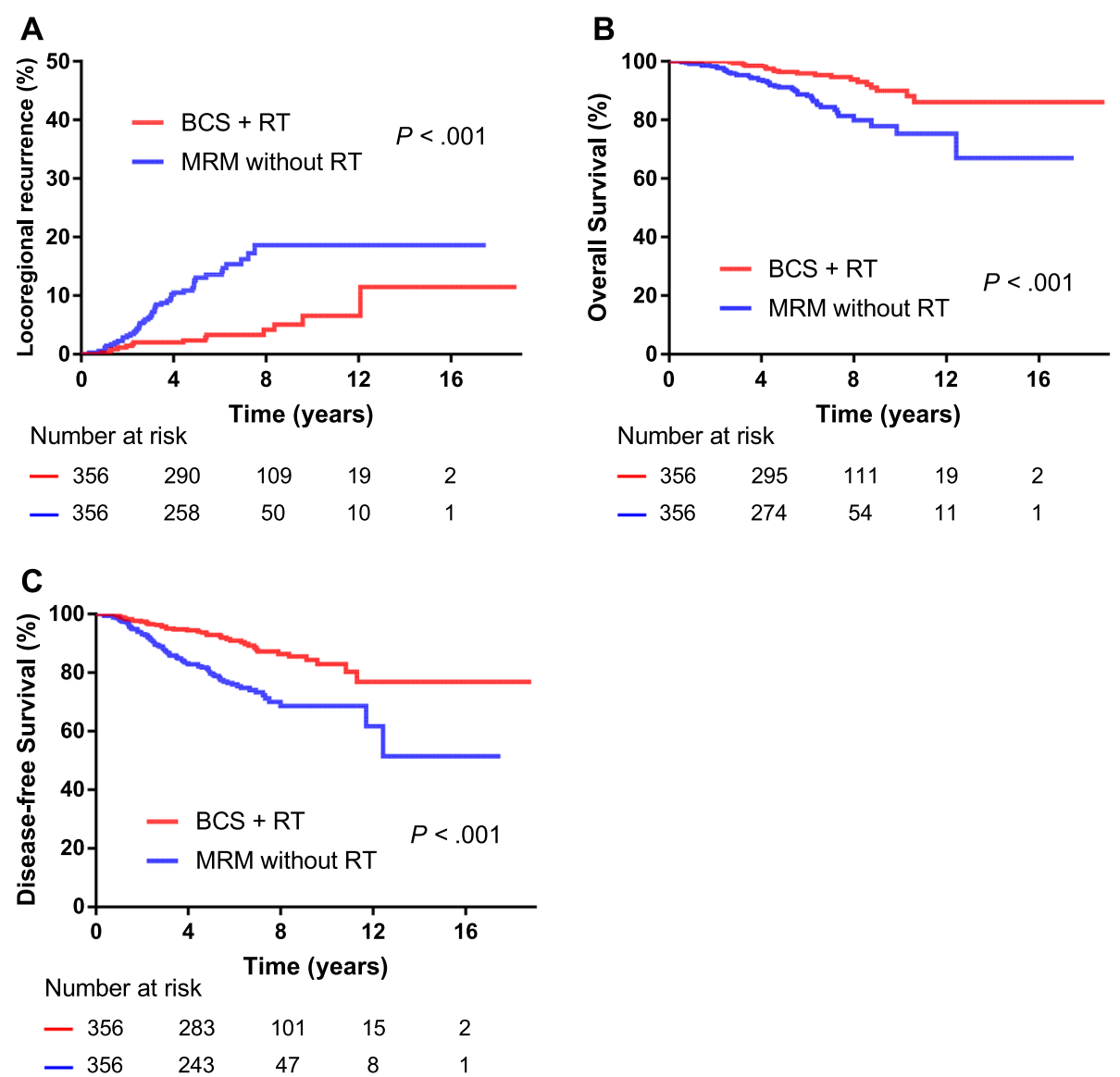

Fig. 2 Kaplan-Meier plots showing locoregional recurrence, overall survival and disease-free survival between the BCS + RT group and the MRM without RT group. MRM = modified radical mastectomy; $B C S=$ breast-conserving surgery; $R T$ = radiotherapy.

.009). Surgery procedure (BCS vs. MRM) was not associated with either LRR $(P=.996)$, OS $(P=.495)$ or DFS $(P=.204)$.

\section{Comparison of survival outcomes between subgroups with propensity score analysis}

The demographics, tumor, and treatment characteristics are summarized and matched by propensity score analysis between $\mathrm{BCS}+\mathrm{RT}$ and MRM without RT groups, and between $\mathrm{BCS}+\mathrm{RT}$ and $\mathrm{MRM}+\mathrm{RT}$ groups (Tables S1, S2). The characteristics were well balanced between the groups post-match. After match, BCS + RT group showed a significantly lower 5-year LRR rate (2.4\% vs. $13.1 \%, P<.001)$, and higher 5 -year OS rate (96.3\% vs. $91.1 \% ; P<.001)$ and DFS rate compared with MRM without RT group (92.9\% vs. $79.7 \%$, respectively; $P<.001)$ (Fig. 2). However, there was no significant difference in 5 -year LRR rate $(2.1 \%$ vs. $4.2 \%, P=.915)$, OS rate $(95.8 \%$ vs. $96.2 \%, P=.768)$ or DFS rate between $\mathrm{BCS}+\mathrm{RT}$ and MRM + RT groups $(93.3 \%$ vs. $85.3 \%$, respectively; $P=.156$ ) (Fig. 3).

\section{Discussion}

The present study compared the efficacy of BCS + RT with MRM in T1-2N1M0 breast cancer patients. The 5year OS and DFS rates in the BCS + RT group were significantly higher than the MRM group. $\mathrm{BCS}+\mathrm{RT}$ group had more favorable characteristics compared with the MRM group. Multivariate analysis revealed that the breast surgery procedure was not independently associated with patient survival. Further PSM analysis showed that the $\mathrm{BCS}+\mathrm{RT}$ group had comparable survival outcomes with the MRM + RT group, and patients without RT exhibited worse survival rates than those that received RT regardless of surgery procedures.

It has been demonstrated in early randomized controlled studies [15] that BCS + RT is at least equivalent, or in recent population-based retrospective studies $[6,7$, $11,16,17]$, that BCS + RT is even superior to mastectomy. Although the findings of randomized controlled trials are often considered high-level clinical evidences, their specialized research environment may differ from the environment in which large populations are located [18]. The randomized controlled studies based on a 

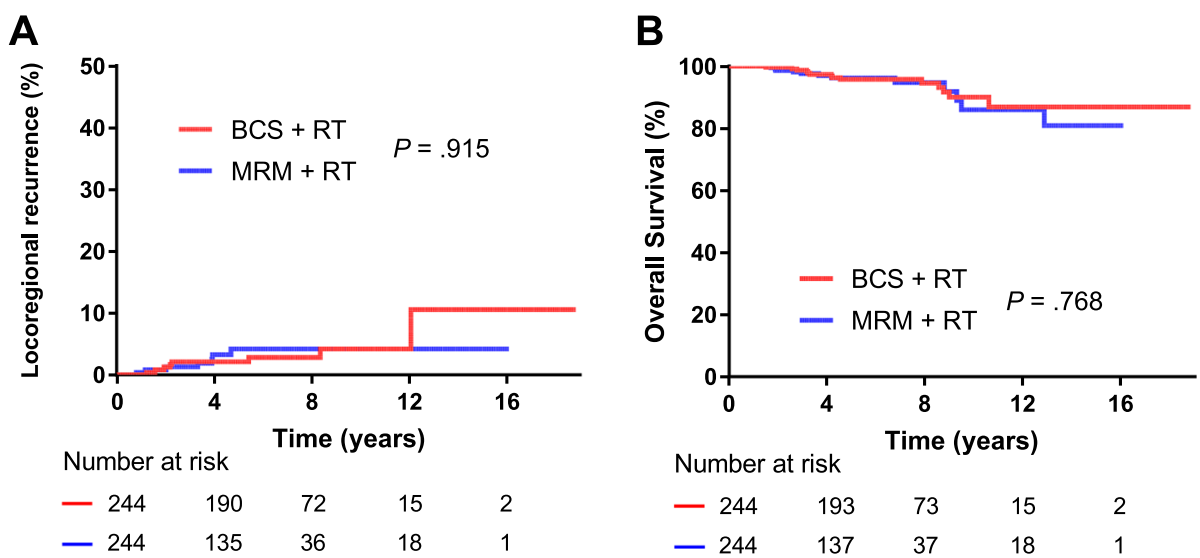

Number at risk

$\begin{array}{lllll}-244 & 193 & 73 & 15 & 2 \\ -244 & 137 & 37 & 18 & 1\end{array}$

C

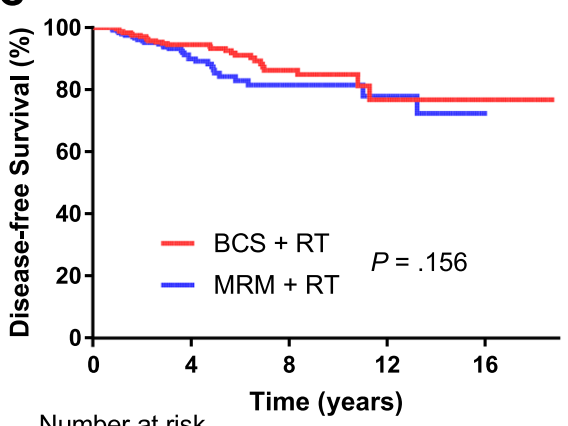

Number at risk

$\begin{array}{rrrrr}-244 & 188 & 65 & 12 & 2 \\ -244 & 128 & 34 & 17 & 1\end{array}$

Fig. 3 Kaplan-Meier plots showing locoregional recurrence, overall survival and disease-free survival between the MRM with RT and BCS with RT groups. $\mathrm{MRM}=$ modified radical mastectomy; $\mathrm{BCS}=$ breast-conserving surgery; RT = radiotherapy.

specific patient population and a specific research environment may not truly reflect the actual medical environment, the process of diagnosis and treatment, and the health status of patients under real conditions, thus leading to the failure to achieve the same results in the real world.

The present study explored why BCS + RT is superior to mastectomy, focusing on patients with T1-2N1M0 breast cancers. Multivariate analysis and PSM were performed to minimize the effects of confounding due to differences in the distribution of risk factors between treatment groups. Results showed that the survival benefit of BCS over MRM appears to be related to the combination of BCS and adjuvant RT rather than the surgical procedure. Similarly, previous reports have shown that BCS $+\mathrm{RT}$ resulted in better overall survival than mastectomy without RT in patients with stage I-II [6] or stage I-III breast cancer [16, 19] after accounting for factors related to treatment selection. Kim et al. found that in patients with $\mathrm{T} 1-2 \mathrm{~N} 1$ triple-negative breast cancer, $\mathrm{BCS}+\mathrm{RT}$ provided significantly higher OS than MRM without RT. [20] In contrast, a Dutch study showed that, after adjusting for confounders, $\mathrm{BCS}+\mathrm{RT}$ improved 10-year breast cancer-specific survival compared with mastectomy without RT, however the difference was only observed in a subset of patients with T1N0 stage disease, not in patients with T1N1, T2N0, or T2N1 stages of disease [10]. One explanation for this inconsistent finding compared with our study might be that $52 \%$ of patients in the T1-2N1 subgroup had not received chemotherapy (compared with $6 \%$ of patients in our study), as the survival benefit of RT is dependent on well-controlled distant disease with adequate systemic therapy. Recently, using a larger number of samples, a Dutch study showed superior long-term breast cancer-specific survival with BCS + RT than mastectomy $\pm \mathrm{RT}$ in patients with $\mathrm{T} 1 \mathrm{~N} 1$ and $\mathrm{T} 2 \mathrm{~N} 1$ diseases, but the use of postmastectomy radiotherapy was not analyzed separately [21].

The present study indicated that radiotherapy played an important role in improving the survival outcomes for patients with $\mathrm{T} 1-2 \mathrm{~N} 1$ breast cancer, and clinicians should be cautious to omit radiotherapy after mastectomy in this group, although increasing data showed low-risk of locoregional recurrences in T1-2N1 breast cancer treated with modern systemic therapy [22-24]. We found that the BCS + RT group had comparable 
survival outcomes with the MRM + RT group, but the radiation volume in the two groups was not the same. Less proportion of patients in the BCS + RT group received regional nodal irradiation (RNI) than in the $M R M+R T$ group. This might be due to the fact that there were more patients with favorable prognostic factors in the $\mathrm{BCS}+\mathrm{RT}$ group than in the $\mathrm{MRM}+\mathrm{RT}$ group, reflecting the controversy and the selective use of RNI in N1 patients within our practice. In addition, RNI was mainly delivered to the supra-/infraclavicular region, and less than $10 \%$ of patients received internal mammary nodal irradiation. If the patients in this study had received comprehensive RNI including internal mammary nodes, the more improved outcomes of RT group could have been observed, because DFS improvement resulting from supraclavicular plus internal mammary nodal irradiation was found in two recent randomized studies [25, 26].

To our knowledge, the present study is one of the few studies that has investigated the role of both surgical procedure and radiotherapy in patients with T12N1 stage breast cancer. An important strength of our study was the inclusion of data from two large cancer centers to thoroughly investigate the role of radiotherapy by comparing the survival outcomes between three groups, including BCT + RT, MRM with RT, and MRM without RT. Furthermore, our study accounts for as many confounding factors as possible. Although, adjusting for prognostic risk factors did not completely reduce the selection bias. Christiansen et al. reported that patients with more comorbidity were preferably treated by mastectomy, which reduced the survival in the mastectomy group [11]. In the present study, the death was mostly due to breast cancer and the OS rates likely reflect breast cancerspecific survival. In addition, disease-free survival was analyzed in our study to estimate treatment effects more reliably than overall survival by eliminating the influence of other factors leading to non-breast cancer deaths, such as comorbidities. The consistent conclusions of treatment effects on DFS and OS in the present study result in more robust findings.

Some limitations of our study should be noted. First, the proportion of BCS vs MRM in this cohort was $10 \%$ vs. $90 \%$, which is opposite to what we see in the real world (BCS vs. MRM is usually $70 \%$ vs. $30 \%$ ). However, the study using the National Cancer Data Base demonstrated increasing mastectomy rates in patients eligible for BCS with coincident increases in breast reconstruction and bilateral mastectomy [27]. Thus, the findings might be clinically relevant not only in China but also in the rest of world. Second, after developments in diagnostic and therapeutic strategies, treatment guidelines for patients with breast cancer have changed and our study population may not reflect the outcomes for patients currently being treated. For example, the present study population showed a decrease in anti-Her2 targeted therapy use compared with the current treatment standards; however, as this factor applies for both BCS + RT and mastectomy, it is not expected to have biased the results. Meanwhile, the findings may be valid only in those with macrometastasis rather than micrometastasis in axilla, because only $3.8 \%$ of the patients received sentinel node biopsy. It has been shown that extensive pathologic assessment of sentinel nodes results in frequent identification of micrometastatic foci and the use of PMRT in patients with small-volume nodal disease should be conservative [28]. Third, the adjustment for registered characteristics might not exclude residual confounding, and selection bias still potentially had influence on the estimation of treatment effects.

\section{Conclusion}

Based on our real world analyses, we found that postoperative radiotherapy rather than the surgery procedures was associated with superior survival outcomes in patients with T1-2N1M0 breast cancer. These findings need further validation.

\section{Supplementary Information}

The online version contains supplementary material available at https://doi. org/10.1186/s12885-020-07646-y.

Additional file 1: Table S1. Baseline characteristics of patients in MRM without RT and BCS + RT groups before and after match. Table S2. Baseline characteristics of patients in MRM + RT and BCS + RT groups preand post-matched by propensity score analysis.

\begin{abstract}
Abbreviations
BCS: Breast-conserving surgery; BCS + RT: Breast-conserving surgery plus radiotherapy; DFS: Disease-free-survival; ER: Estrogen receptor; HER2: Human epidermal growth factor receptor 2; LRR: Locoregional recurrence;

MRM: Modified radical mastectomy; MRM + RT: Modified radical mastectomy plus radiotherapy; OS: Overall survival; RT: Radiotherapy;

PMRT: Postmastectomy radiotherapy; PR: Progesterone receptor;

PSM: Propensity score-matching
\end{abstract}

\section{Acknowledgements}

Not applicable.

\section{Authors' contributions}

GYS, GW and YJZ: Formal analysis, investigation, data collection, methodology, and writing of first draft; $Y(Y U) T, H J$, JYW, JHZ, YY, JJ, YWS, YPL, HF, HR, Y (Yuan)T, SNQ, NL, BC and NNL: Review and editing of the manuscript and collected data, XRZ, SYC: Data collection and statistical analysis; SLW and YXL: Design, formal analysis, validation and statistical analysis guidance. All authors have read and approved the manuscript.

\section{Funding}

The present study was supported by the National Key Projects of Research and Development of China (2016YFC0904600), Beijing Clinical Application Research Project (Z171100001017116), and National Natural Science Foundation of China 81972860). These funding bodies were independent of the study design, data collection, interpretation and manuscript writing. 


\section{Availability of data and materials}

The datasets used and/or analysed during the current study are available from the corresponding author on reasonable request.

\section{Ethics approval and consent to participate}

This study was approved by Institutional Review Board of Cancer Hospital, Chinese Academy of Medical Sciences and Peking Union Medical College (approval number 15-057/984) and informed consent is waived from Institutional Review Board as its retrospective nature.

\section{Consent for publication}

Not applicable.

\section{Competing interests}

The authors declare that they have no competing interests.

\section{Author details}

'State Key Laboratory of Molecular Oncology and Department of Radiation Oncology, National Cancer Center/National Clinical Research Center for Cancer/Cancer Hospital, Chinese Academy of Medical Sciences and Peking Union Medical College, Beijing 100021, China. ${ }^{2}$ Department of Radiation Oncology, Sun Yat-sen University Cancer Center, State Key Laboratory of Oncology in South China, Collaborative Innovation Center of Cancer Medicine, Guangzhou 510060, China. ${ }^{3}$ Department of Radiation Oncology, The Third Affiliated Hospital of Guangzhou Medical University, Guangzhou 510150, China.

Received: 12 June 2020 Accepted: 17 November 2020 Published online: 26 November 2020

\section{References}

1. Arriagada R, Le MG, Rochard F, Contesso G. Conservative treatment versus mastectomy in early breast cancer: patterns of failure with 15 years of follow-up data. Institut Gustave-Roussy breast Cancer group. J Clin Oncol. 1996;14(5):1558-64. https://doi.org/10.1200/JCO.1996.14.5.1558.

2. Fisher B, Anderson S, Bryant J, et al. Twenty-year follow-up of a randomized trial comparing total mastectomy, lumpectomy, and lumpectomy plus irradiation for the treatment of invasive breast cancer. N Engl J Med. 2002; 347(16):1233-41. https://doi.org/10.1056/NEJMoa022152.

3. Jacobson JA, Danforth DN, Cowan KH, et al. Ten-year results of a comparison of conservation with mastectomy in the treatment of stage I and II breast cancer. N Engl J Med. 1995;332(14):907-11. https://doi.org/10. 1056/NEJM199504063321402.

4. Lichter AS, Lippman ME, Danforth DN Jr, et al. Mastectomy versus breastconserving therapy in the treatment of stage I and II carcinoma of the breast: a randomized trial at the National Cancer Institute. J Clin Oncol. 1992;10(6):976-83. https://doi.org/10.1200/JCO.1992.10.6.976.

5. Litière $\mathrm{S}$, Werutsky $\mathrm{G}$, Fentiman $\mathrm{IS}$, et al. Breast conserving therapy versus mastectomy for stage I-II breast cancer: 20 year follow-up of the EORTC 10801 phase 3 randomised trial. Lancet Oncol. 2012;13(4):412-9. https://doi. org/10.1016/s1470-2045(12)70042-6.

6. Hwang ES, Lichtensztajn DY, Gomez SL, Fowble B, Clarke CA. Survival after lumpectomy and mastectomy for early stage invasive breast cancer: the effect of age and hormone receptor status. Cancer. 2013;119(7):1402-11. https://doi.org/10.1002/cncr.27795.

7. Agarwal S, Pappas L, Neumayer L, Kokeny K, Agarwal J. Effect of breast conservation therapy vs mastectomy on disease-specific sunvival for early-stage breast cancer. JAMA Surg. 2014;149(3):267-74. https:/doi.org/10.1001/jamasurg.2013.3049.

8. Hartmann-Johnsen OJ, Karesen R, Schlichting E, Nygard JF. Survival is better after breast conserving therapy than mastectomy for early stage breast Cancer: a registry-based follow-up study of Norwegian women primary operated between 1998 and 2008. Ann Surg Oncol. 2015;22(12):3836-45. https://doi.org/10.1245/s10434-015-4441-3.

9. Hofvind S, Holen A, Aas T, Roman M, Sebuodegard S, Akslen LA. Women treated with breast conserving surgery do better than those with mastectomy independent of detection mode, prognostic and predictive tumor characteristics. Eur J Surg Oncol. 2015;41(10):1417-22. https://doi.org/10.1016/j.ejso.2015.07.002.

10. van Maaren MC, de Munck $L$, de Bock $G H$, et al. 10 year survival after breastconserving surgery plus radiotherapy compared with mastectomy in early breast cancer in the Netherlands: a population-based study. Lancet Oncol. 2016;17(8):1158-70. https://doi.org/10.1016/s1470-2045(16)30067-5.
11. Christiansen P, Carstensen SL, Ejlertsen B, et al. Breast conserving surgery versus mastectomy: overall and relative survival-a population based study by the Danish breast Cancer cooperative group (DBCG). Acta Oncol. 2018; 57(1):19-25. https://doi.org/10.1080/0284186X.2017.1403042.

12. Li J, Zhang BN, Fan JH, et al. A nation-wide multicenter 10-year (1999-2008) retrospective clinical epidemiological study of female breast cancer in China. BMC Cancer. 2011;11:364. https://doi.org/10.1186/1471-2407-11-364.

13. Nordenskjold $A E$, Fohlin $H$, Albertsson $P$, et al. No clear effect of postoperative radiotherapy on survival of breast cancer patients with one to three positive nodes: a population-based study. Ann Oncol. 2015;26(6): 1149-54. https://doi.org/10.1093/annonc/mdv159.

14. Burstein HJ, Curigliano G, Loibl S, et al. Estimating the benefits of therapy for early stage breast Cancer the St Gallen international consensus guidelines for the primary therapy of early breast Cancer 2019. Ann Oncol. 2019. https://doi.org/10.1093/annonc/mdz235.

15. Early Breast Cancer Trialists' Collaborative G. Effects of radiotherapy and surgery in early breast cancer. An overview of the randomized trials. N Engl J Med. 1995;333(22):1444-55. https://doi.org/10.1056/NEJM199511303332202.

16. Chen K, Liu J, Zhu L, Su F, Song E, Jacobs LK. Comparative effectiveness study of breast-conserving surgery and mastectomy in the general population: A NCDB analysis. Oncotarget. 2015;6(37):40127-40. https://doi. org/10.18632/oncotarget.5394.

17. Landercasper J, Ramirez LD, Borgert AJ, et al. A reappraisal of the comparative effectiveness of lumpectomy versus mastectomy on breast Cancer survival: a propensity score-matched update from the National Cancer Data Base (NCDB). Clin Breast Cancer. 2019;19(3):e481-93. https://doi. org/10.1016/j.clbc.2019.02.006.

18. Sherman RE, Anderson SA, Dal Pan GJ, et al. Real-world evidence - what is it and what can it tell us? N Engl J Med. 2016;375(23):2293-7. https://doi.org/ 10.1056/NEJMsb1609216.

19. Onitilo AA, Engel JM, Stankowski RV, Doi SA. Survival comparisons for breast conserving surgery and mastectomy revisited: community experience and the role of radiation therapy. Clin Med Res. 2015;13(2):65-73. https://doi.org/10.3121/cmr. 2014.1245.

20. Kim K, Park HJ, Shin $\mathrm{KH}$, et al. Breast conservation therapy versus mastectomy in patients with T1-2N1 triple-negative breast Cancer: pooled analysis of KROG 14-18 and 14-23. Cancer Res Treat. 2018;50(4):1316-23. https://doi.org/10.4143/crt.2017.575.

21. Lagendijk M, van Maaren MC, Saadatmand S, et al. Breast conserving therapy and mastectomy revisited: breast cancer-specific survival and the influence of prognostic factors in 129,692 patients. Int J Cancer. 2018;142(1): 165-75. https://doi.org/10.1002/ijc.31034.

22. Bazan JG, Majithia L, Quick AM, et al. Heterogeneity in outcomes of pathologic T1-2N1 breast Cancer after mastectomy: looking beyond Locoregional failure rates. Ann Surg Oncol. 2018;25(8):2288-95. https://doi. org/10.1245/s10434-018-6565-8.

23. Lai SF, Chen $\mathrm{YH}, \mathrm{Kuo} \mathrm{WH}$, et al. Locoregional recurrence risk for Postmastectomy breast Cancer patients with T1-2 and one to three positive lymph nodes receiving modern systemic treatment without radiotherapy. Ann Surg Oncol. 2016;23(12):3860-9. https://doi.org/10.1245/s10434-016-5435-5.

24. Muhsen S, Moo TA, Patil S, et al. Most breast Cancer patients with T1-2 tumors and one to three positive lymph nodes do not need Postmastectomy radiotherapy. Ann Surg Oncol. 2018;25(7):1912-20. https:// doi.org/10.1245/s10434-018-6422-9.

25. Poortmans PM, Collette $\mathrm{S}$, Kirkove $\mathrm{C}$, et al. Internal mammary and medial supraclavicular irradiation in breast Cancer. N Engl J Med. 2015;373(4):31727. https://doi.org/10.1056/NEJMoa1415369.

26. Whelan TJ, Olivotto IA, Parulekar WR, et al. Regional nodal irradiation in early-stage breast Cancer. N Engl J Med. 2015;373(4):307-16. https://doi.org/ 10.1056/NEJMoa1415340.

27. Kummerow KL, Du L, Penson DF, Shyr $Y$, Hooks MA. Nationwide trends in mastectomy for early-stage breast cancer. JAMA Surg. 2015;150(1):9-16. https://doi.org/10.1001/jamasurg.2014.2895.

28. Chang JS, Lee J, Kim KH, et al. Do recent advances in diagnostic and therapeutic procedures negate the benefit of Postmastectomy radiotherapy in $\mathrm{N} 1$ patients with a low risk of Locoregional recurrence? Medicine (Baltimore). 2015;94(33):e1259. https://doi.org/10.1097/MD.0000000000001259.

\section{Publisher's Note}

Springer Nature remains neutral with regard to jurisdictional claims in published maps and institutional affiliations. 